\title{
Costs and outcomes of an intervention programme for offenders with personality disorders
}

\author{
Barbara Barrett and Sarah Byford
}

\section{Background}

The dangerous severe personality disorder programme was developed in high secure prisons and hospitals at great expense to identify and treat the most dangerous offenders with personality disorders.

\section{Aims}

To evaluate whether the long-term costs of the programme are greater or less than the long-term outcomes.

\section{Method}

We used a Markov decision model with a cost-effectiveness analysis to determine the incremental cost of the programme per serious offence prevented and a cost-offset analysis to consider whether monetary benefits were greater than costs.

\section{Results}

Costs were consistently higher for the intervention

programme and the cost per serious offence prevented was over $f 2$ million, although there was some evidence that adjustments to the programme could lead to similar interventions becoming cost-effective.

\section{Conclusions}

Little evidence was found to support the cost-effectiveness of the intervention programme for offenders with personality disorders, although delivery of the programme in a lowercost prison would probably yield greater benefits than costs. There are frequent calls for mentally disordered offenders to be detained in secure hospitals rather than prisons; however, if reoffending remains the outcome of interest for policy makers, it is likely that the costs of detention in hospital will remain greater than the benefits for dangerous offenders with a personality disorder.

\section{Declaration of interest}

None.
The treatment, detention and punishment of dangerous offenders with personality disorders are a concern for all criminal justice and mental health systems. Debates persist over whether such offenders are criminals who should be held in prisons, or patients who should be treated in hospital, or indeed whether they can be treated at all. ${ }^{1,2}$ What is generally accepted, however, is that offenders with personality disorders, particularly the most dangerous ones, consume considerable amounts of resources in the criminal justice and healthcare systems. Indeed in recent years in the UK, substantial amounts of money have been spent on developing and running specialist services for the most dangerous offenders with a personality disorder: the dangerous severe personality disorder (DSPD) programme. The programme was created by the UK government in 1999 and describes a set of services for an estimated 1400 men in prisons and a further 400 in psychiatric hospitals who have a severe personality disorder linked to a high risk of serious reoffending. ${ }^{3}$ The DSPD treatment programmes were stand-alone units in high secure hospitals and prisons and they employed a range of therapeutic approaches including cognitive-behavioural therapy and dialectical behaviour therapy, ${ }^{4}$ where the aim was to motivate change and reduce the risk of serious reoffending.

The DSPD programme was expensive, ${ }^{5}$ although very little is known about whether the additional spending was worthwhile in terms of improvements in outcomes. A number of papers have sought to evaluate the costs and benefits of intervention programmes for similar populations; Prentky \& Burgess ${ }^{6}$ developed a model to evaluate the Massachusetts Treatment Centre for repetitive violent sex offenders and found that there appeared to be monetary benefits to the rehabilitation of sex offenders. A similar study by Shanahan \& Donato ${ }^{7}$ evaluated a cognitive-behavioural treatment programme for paedophiles in Australian prisons and found that there was some evidence of the cost-effectiveness of the programme, although conclusions depended on the assumptions made in the model.

We have previously reported on the costs and outcomes of the DSPD assessment programme where we found that assessment was costly, lengthy and resulted in worse outcomes for offenders. ${ }^{5}$ We report here the results of an economic evaluation of the longer and more resource intensive DSPD treatment programme. During a time in which resources in both criminal justice and healthcare sectors are limited, economic evaluation is important to help to identify areas where the costs are not worthwhile in terms of the outcomes achieved. The aim of this study is to evaluate whether the long-term costs of the DSPD programme are greater or less than the long-term outcomes.

\section{Method}

\section{Decision modelling}

Economic evaluations are often undertaken alongside prospective studies that measure clinical outcomes. For example, an evaluation of the cost-effectiveness of cognitive-behavioural therapy for borderline personality disorder was undertaken alongside a clinical evaluation of its effectiveness. ${ }^{8}$ However, in some cases a prospective evaluation is not possible, when the outcome of interest, here serious reoffending among life-sentence prisoners, would require a prohibitively long follow-up period, or when a service is universally available and there is little support for a 'do-nothing' comparison group. When a prospective evaluation is not feasible or not possible, an economic evaluation can be undertaken using decision modelling. Decision models use mathematical relationships to define the possible consequences that flow from a set of alternative options being evaluated and are a structured way of thinking about how a decision taken now has an impact on costs and outcomes in the future. ${ }^{9}$ Thus, 
rather than waiting for the results of a formal evaluation, in decision models results are generated by modelling existing data on costs and outcomes.

\section{Markov decision model of DSPD programme}

We present a Markov decision model of the costs and outcomes of an intervention programme (the DSPD programme) compared with usual care in prisons and hospitals for offenders with personality disorders. Costs are considered from a service perspective and the outcome measure is serious reoffending. In the comparison arm we assumed the offenders with personality disorders were detained in mainstream high secure prisons or hospitals and that they proceeded through their sentence without receiving any specialist intervention beyond existing offending behaviour programmes such as the sex offender treatment and the violent offender treatment programmes.

In order to undertake an economic evaluation using a decision model, it is necessary to develop a model structure that reflects the intervention and comparator, identify suitable probabilities for transition between states and identify suitable costs and outcomes for each state. This model was developed and populated on the basis of a series of reviews (full details available from the authors on request): (a) a review of policy documents related to the DSPD programme; (b) a systematic review of the literature on services, outcomes and costs for offenders with personality disorders, and those convicted of serious violent and sexual offences, those detained in high secure institutions and offenders with a personality disorder; and (c) a systematic review of the literature on services, outcomes and costs for individuals detained in secure hospitals.

Where the review was not able to identify a suitable variable, for example if a transition probability was specific to the functioning of the DSPD programme, or where a range of estimates were available and advice was needed on which population was closest to offenders with personality disorders, estimates were developed through meetings with those running the services and at the Ministry of Justice.

The basic structure of the model is shown in Fig. 1. In Markov models, individuals are defined as being in one of a number of specified states (depicted as ovals) during each Markov cycle, which is a specified period of time. At the end of each cycle it is possible to move between states (the paths are depicted by arrows) according to probabilities, and costs and outcomes are incurred in each state. Figure 1 shows the phases of detention in prison or in a high secure hospital for an offender with personality disorder where, following 2 years of treatment, the individual begins in a high secure establishment and then moves into lower security before being released into the community. In the intervention programme (DSPD) arm of the model, individuals spend additional time in treatment and are not released unless following treatment their risk of reoffending is considered to be low. For both the intervention programme and usual care, once the offender is released into the community, they can remain in the community, be reconvicted of a minor offence or breach their licence, or be reconvicted of a serious offence. A serious reconviction results in the person returning to prison.

\section{Probabilities}

All model parameters are listed in Table 1. A key transition probability was the annual rate of serious reconviction among offenders with personality disorders released into the community, for those who had been through the intervention programme and those who had not. The systematic review identified a number of papers where rates of serious reconviction following specialist and mainstream incarceration were reported, with annual rates of reconviction of between 2 and 5\%. ${ }^{9-11}$ Following specialist treatment, offenders would only be released if they were considered to have a low probability of reoffending, so an annual reconviction rate of $3 \%$ was assumed. For the comparator where offenders had progressed through the criminal justice system as usual, an annual rate of $5 \%$ was assumed.

\section{Costs and outcomes}

All costs were for the financial year 2005-6 and are listed in full in Table 1. The perspective taken in this evaluation was a service perspective, including costs to criminal justice, health and social services. The costs of 1 year in the intervention (DSPD) treatment services were estimated using the end-of-year financial statements
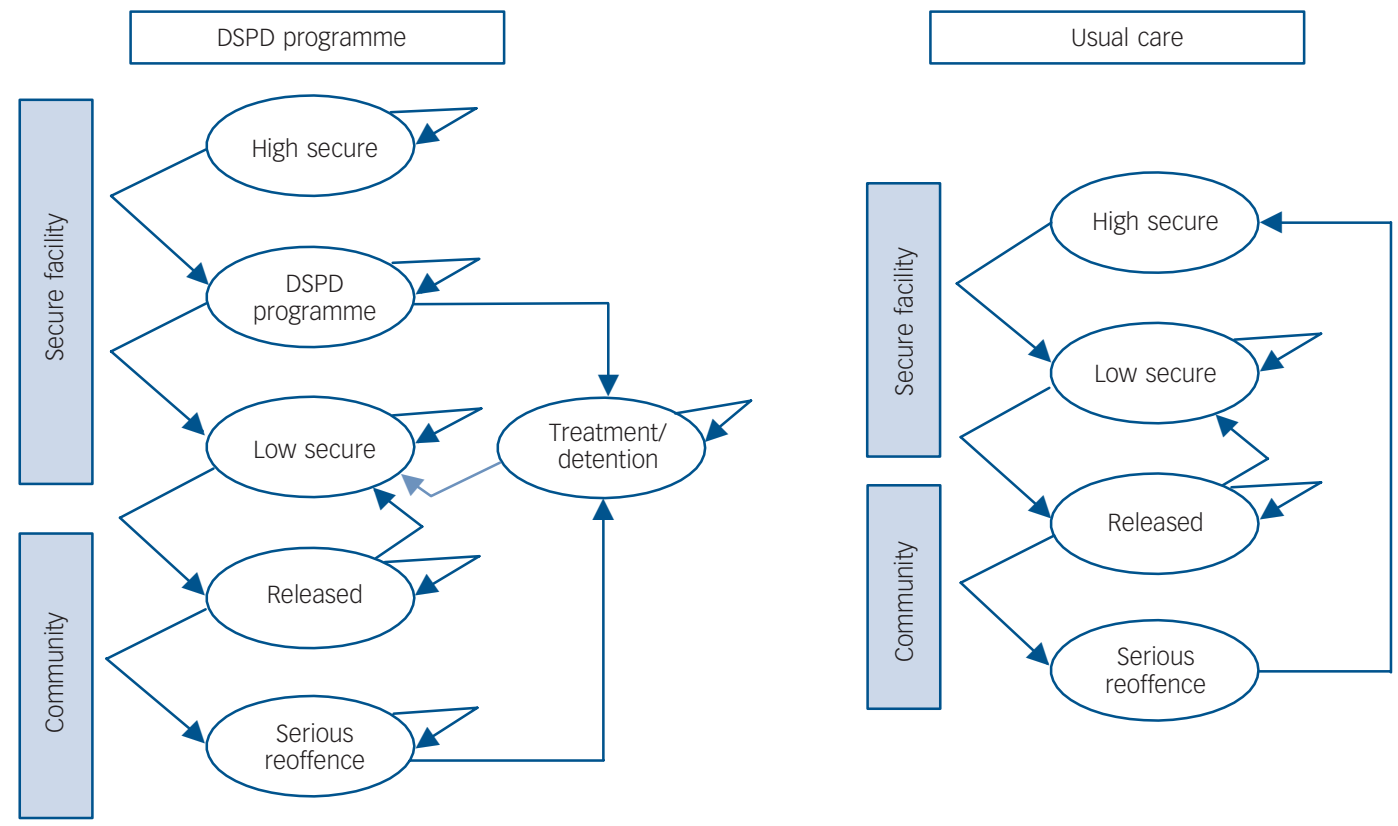

Fig. 1 Basic structure of the dangerous severe personality disorder (DSPD) programme and usual care. 
from each DSPD site. The costs for other Markov states came from various routine sources of unit cost data. ${ }^{16-18}$

Serious reoffending was chosen as the outcome measure because it is the primary outcome of interest to policy makers.

\section{Duration of the model}

The model was run over 25 years in 1-year cycles. Twenty-five years was considered a sufficient period for offenders to pass through the model and be released into the community.

\section{Discounting}

In economic evaluations, it is conventional for future costs and consequences to be stated in terms of their present value. ${ }^{10}$ In their review of guidelines for good practice in decision-analytic modelling, Philips and colleagues ${ }^{9}$ recommended that if the model relates to a long period of time, the same discount rate should be attached to costs and outcomes. For this reason, all costs and outcomes included in this model beyond the first year were discounted at a rate of $3.5 \%$, the rate recommended by both the National Institute for Health and Clinical Excellence ${ }^{11}$ and HM Treasury. ${ }^{12}$

\section{Economic evaluation}

First, the model was analysed using cost-effectiveness analysis. Cohort analysis was used, where the expected value of the intervention programme was calculated by multiplying the percentage of an imaginary cohort in each state by the cost and outcome that have been specified for that state, and summing these to cover all states and stages. This analysis generates estimates over 25 years of the mean expected cost per individual and the mean expected outcomes per individual for both arms of the model, which were then summarised in incremental cost-effectiveness ratios - the difference in mean costs divided by the difference in mean effects. ${ }^{17}$ A judgement on the programme can be made depending on a decision maker's willingness to pay for preventing a serious offence.

The model was then analysed using cost-offset analysis. Here the aim was to compare programme outcomes with programme costs and to establish whether the additional costs of the programme were greater or less than a monetary valuation of outcomes. The cost-offset approach is useful because it allows consideration of both the number and severity of serious offences.

A cost-offset requires the outcome to be valued monetarily. We valued serious reconvictions using estimates developed by the UK Home Office. ${ }^{18,19}$ These include the cost in anticipation of crime (defensive expenditure such as burglar alarms, crime safety information and insurance administration), the cost as a consequence of crime (the physical and emotional impact on victims based on a monetary valuation of quality-adjusted life years, ${ }^{20}$ the cost of victim services and the costs to property) and the costs in response to crime (costs to the criminal justice system, including the police and prison services, and the cost to other services, for example health services who treat the victim of a violent attack). The monetary valuations for serious

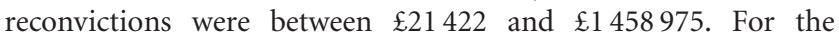
analysis presented here, the base case analysis assumed reconvictions were a mixture of serious wounding and sexual offences and at least half as homicides. In sensitivity analysis, reconvictions were assumed as follows: (a) all reconvictions were serious wounding; (b) all reconvictions were serious sexual offences; and (c) all reconvictions were homicides. The mean expected costs and outcomes for each arm of each model were estimated using cohort analysis. 


\section{Uncertainty}

A number of further sensitivity analyses were undertaken to test the strength and generalisability of the model probabilities, costs and outcomes.

(a) The cost of the intervention (DSPD) programme was varied between the lowest and the highest estimate.

(b) The duration of treatment was reduced from 2 years to 1 .

(c) The probability of serious reoffending was varied for both arms of the models between 0 and 5\%.

(d) The discount rate was varied between 0 and $6 \%$.

Monte Carlo simulation was used to consider the impact of parameter uncertainty on outcomes in the cost-effectiveness analysis. The sum of the costs and outcomes for the series of states traversed by an individual passing through the model were calculated with an algorithm selecting values from the possible distributions of probabilities, costs and outcomes ${ }^{21}$ and the distributions were then used to plot cost-effectiveness acceptability curves. The cost-effectiveness acceptability curves show the probability that the intervention programme for offenders with personality disorders is cost-effective compared with usual care for a range of maximum monetary values that a decision maker might be willing to pay for a unit reduction in serious reoffending. ${ }^{22}$

\section{Results}

\section{Cost-effectiveness analysis}

The costs and outcomes determined by the model are detailed in Table 2. Costs were $£ 927048$ per offender over 25 years in the intervention programme arm and $£ 485208$ per offender in the usual care arm. The higher costs ( $£ 441840)$ were accompanied by lower average rates of serious offences in the intervention programme arm ( 0.048 per offender over 25 years) compared with the usual care arm ( 0.246 per offender over 25 years). The analysis showed that the incremental cost of the intervention programme per serious offence prevented was $\mathfrak{£} 2.24$ million.

The cost-effectiveness acceptability curve in Fig. 2 shows graphically the probability that the intervention (DSPD) programme was more cost-effective than the alternative for different values that a decision maker might be willing to pay per serious offence prevented. The curve suggests that the programme was not a cost-effective intervention because at no point does the curve move above $40 \%$ for willingness to pay values of up to $\mathfrak{£} 5$ million.

The sensitivity analyses test the assumptions used in the base case analysis.

(a) If the intervention programme took place in a low-cost prison site, the incremental cost per serious offence prevented would

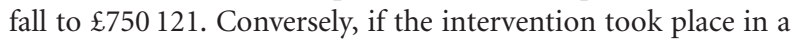
high-cost hospital site, the incremental cost per serious offence prevented would rise to $\mathfrak{£} 3540377$.

(b) If the duration of the programme was reduced to 1 year, the incremental cost per serious offence prevented would fall to $\mathfrak{E} 771538$.

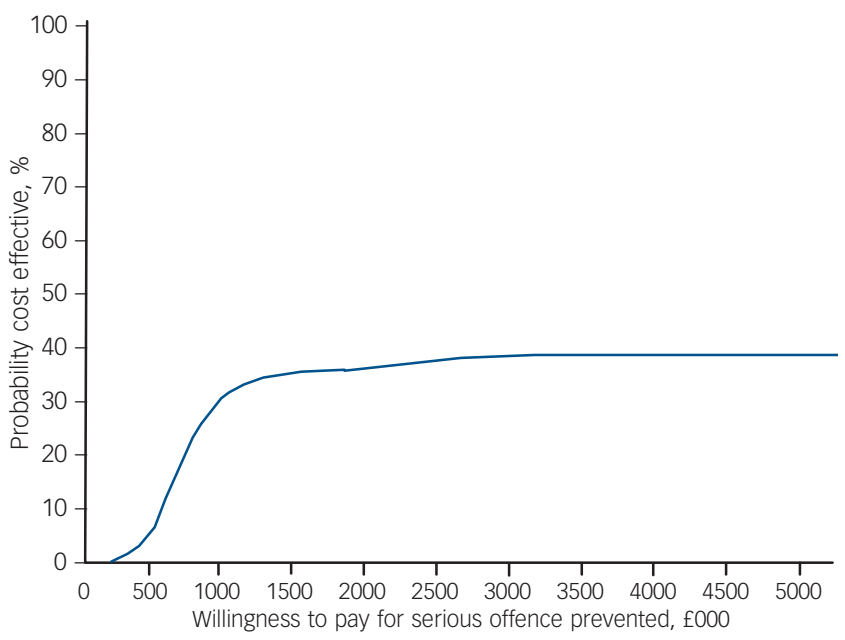

Fig. 2 Cost-effectiveness acceptability curve.

The probability that the intervention programme for offenders with personality disorders is cost-effective compared with usual care for different values a decision maker might be willing to pay for a serious offence prevented.

(c) If the reconviction rate was $2 \%$ in the intervention programme arm and $6 \%$ in the usual care arm, the incremental cost per

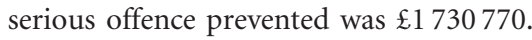

(d) If no discount rate is applied, the incremental cost per serious offence prevented was $£ 1527365$; if the discount rate is increased to $6 \%$, the incremental cost per serious offence prevented was to $£ 2913565$.

\section{Cost-offset analysis}

The base case cost-offset analysis suggested that when outcomes were valued monetarily, the incremental costs of the intervention programme ( $£ 441840$ per person over 25 years) were greater than the incremental benefits (reductions in serious reoffences) (£149244 per person over 25 years).

(a) If all reoffences were serious wounding, the incremental costs of the programme were $\mathfrak{£} 437598$ greater than benefits.

(b) If all reoffences were serious sexual offences, the incremental costs of the programme were $£ 426860$ greater than benefits.

(c) If all reoffences were assumed to be homicides, the incremental costs of the programme were $\mathfrak{£} 152963$ greater than benefits.

The same sensitivity analyses were applied to the cost-offset analysis as used for the cost-effectiveness analysis and these are summarised in Table 3. Costs were greater than the monetary valuation of outcomes for all but one of the analyses presented; if the programme was based in a low-cost prison site, then benefits are $\mathfrak{E} 711$ more than costs.

\section{Discussion}

\section{Main findings}

Economic evaluation using decision modelling can be a useful way of considering cost-effectiveness when a prospective trial is not possible or practicable. We used this technique to estimate the

$\begin{array}{lcc}\text { Table } 2 \text { Model-determined costs and outcomes per offender over } 25 \text { years } & \begin{array}{c}\text { No dangerous severe personality } \\ \text { disorder programme } \\ \text { disorder programme }\end{array} & 485208 \\ \text { Costs in f, mean } & 927048 & 0.246 \\ \text { Outcomes: serious offences, mean } & 0.048 & 441840\end{array}$




\begin{tabular}{|c|c|c|c|}
\hline Sensitivity analysis & $\begin{array}{l}\text { Incremental cost } \\
\text { per person over } 25 \text { years, } \mathrm{f}\end{array}$ & $\begin{array}{l}\text { Monetary valuation of incremental benefit } \\
\text { per person over } 25 \text { years, } f\end{array}$ & Cost-offset \\
\hline Base case & 441840 & 149244 & 292596 \\
\hline Low-cost prison & 148533 & 149244 & -711 \\
\hline High-cost hospital & 701039 & 149244 & 551795 \\
\hline 1-year programme & 149160 & 145475 & 3685 \\
\hline Reoffending ${ }^{\mathrm{a}}$ & 441840 & 186019 & 255821 \\
\hline 0\% discount & 536960 & 265323 & 271637 \\
\hline $6 \%$ discount & 391476 & 101004 & 290472 \\
\hline
\end{tabular}

long-term costs and outcomes of an intervention programme for offenders with personality disorders over a 25 -year period because the outcome of interest (reoffences) would not be captured within a standard trial, which generally has far shorter follow-up periods. The results of these analyses do not support the cost-effectiveness of the DSPD intervention programme for offenders with personality disorders.

In the cost-effectiveness analysis, the intervention programme was not cost-effective for all values a decision maker may be willing to pay for preventing a serious offence. In the cost-offset analysis, the expected costs of the programme were consistently greater than the monetary value of the expected benefits. The sensitivity analyses were able to identify the areas of the model where changes in the running of the programme may lead to benefits being greater than costs. First, the DSPD programme was run in both high secure hospitals and high secure prisons; delivery of the programme in a lower-cost prison would probably yield greater benefits than costs. Second, the cost-offset model required a judgement to be made on the severity of the serious offences committed by those released. Benefits were only greater than costs when we assume that all or at least half of these reconvictions were homicides or when the programme was based in a low-cost prison establishment. Although this may be an unlikely scenario, there are no data to verify this, so efforts should be made to record the types of offences offenders with personality disorders commit on release.

Our results were not consistent with earlier economic models in different criminal justice systems that had found evidence of the possible cost-benefit of specialist treatment for serious offenders. ${ }^{5,6}$ However the intervention programme evaluated here, the DSPD programme, was a particularly intensive and lengthy intervention and as levels of serious reoffending are generally low in this population, reductions of a few percentage points in the intervention group did not appear to make the costs worthwhile. A specialist intervention programme for offenders with personality disorders in a mainstream prison establishment, which would be a less costly alternative, may be more likely to be cost-effective. The lack of evidence of the cost-effectiveness of such interventions when based in secure hospitals has implications for future policy. There are frequent calls for mentally disordered offenders to be detained in secure hospitals rather than prisons; ${ }^{23}$ however, if reoffending remains the outcome of interest for policy makers, it is likely that the costs of specialist detention in hospital will remain greater than the benefits for dangerous offenders with a personality disorder.

\section{Limitations}

The model has a number of limitations. First, models are only as good as the quality of data they contain and in this analysis, data were principally taken from relevant literature, but some variables were suggested by those designing and managing the programme. As is common in modelling studies, these data were of variable quality and the existence of gaps in knowledge meant that the model relied heavily on assumptions regarding states, transitions, probabilities, costs and outcomes. The sensitivity analysis allowed the range of possible costs and outcomes to be explored and we anticipate that the models presented here will be adjusted and updated as additional and better quality information becomes available. As such, the model should not be considered an exact representation of the costs and outcomes of the intervention (the DSPD programme), but instead as a useful estimation given current knowledge and as a starting point for further analysis.

The second limitation concerns the outcome measure. The only outcome measure included was rate of serious reconviction, due to limited alternatives in the literature and the preference of the policy makers. Although it would be interesting to incorporate more user-focused outcomes, such as mental health and quality of life, relevant data were unavailable.

Third, conclusions on the cost-offset of the intervention programme depend on the quality of the estimated monetary values of the costs of serious offences. The estimates used in this report were the result of extensive and ongoing work into the monetary valuation of crimes in the UK and should thus be considered the best research that is currently available. Generating an average cost for a particular category of crime is fraught with difficulty, leaving the accuracy of these costs open to question. However, even if the estimates of the costs of serious offences were to increase by twofold, the principal conclusions reported here would not change, i.e. that the intervention programme only appears cost-effective if a large proportion of serious offences were homicides and treatment took place in prisons rather then hospitals. There should be ongoing effort to develop and improve the valuation of serious offences, particularly the monetary valuation of the impact on victims.

Fourth, a significant limitation is that the results of the study stand on the type of serious offences that these offenders with personality disorders commit once released and the unit costs used in the model were for offences of average severity. It is quite possible that dangerous offenders with personality disorders may commit offences of above average seriousness making the monetary valuation of the crime higher, although with so little known on the reconviction patterns of these types of offenders the impact of this is very difficult to estimate. The substantial gap between the expected cost of the programme and the monetary valuation of expected benefits suggests that the potential offences committed by offenders with personality disorders would all have to be extremely serious in order for the programme to be cost-effective.

To generate more accurate models of the costs and outcomes of intervention programmes for the treatment of offenders with 
personality disorders, research should focus on generating better data on the length, location and intensity of such treatment, the probability of serious reoffences by offenders with personality disorders and the types of offences committed by those released.

Barbara Barrett, MSC, PhD, Sarah Byford, MSC, PhD, Health Services and Population Research Department, King's College London, Institute of Psychiatry, London, UK

Correspondence: Barbara Barrett, Centre for the Economics of Mental and Physical Health, Box P024, Institute of Psychiatry, De Crespigny Park, London SE5 8AF, UK. Email: barbara.m.barrett@kcl.ac.uk

First received 19 May 2011, final revision 15 Sep 2011, accepted 11 Nov 2011

\section{Funding}

The study was funded by the Ministry of Justice through the Department of Health Forensic Mental Health Research and Development Programme, but was carried out independently and does not represent the view of either of these bodies.

\section{References}

1 Sarker SP. A British psychiatrist objects to the dangerous and severe personality disorder proposals. J Am Acad Psychiatry Law 2002; 30: 6-9.

2 Haddock A, Snowden P, Dolan M, Parker J, Rees H. Managing dangerous people with severe personality disorder: a survey of forensic psychiatrists' opinions. Psychiatr Bull 2001; 25: 293-6.

3 Home Office, Department of Health. Managing Dangerous People with Severe Personality Disorder: Proposals for Policy Development. Department of Health, 1999.

4 DSPD Programme. Dangerous and Severe Personality Disorder (DSPD) High Secure Services for Men: Planning and Delivery Guide. DSPD Programme, 2005

5 Barrett B, Byford S, Seivewright H, Cooper S, Duggan C, Tyrer P. The assessment of dangerous and severe personality disorder: service use, cost, and consequences. J Forens Psychiatry Psychol 2009; 20: 120-31.

6 Prentky R, Burgess AW. Rehabilitation of child molesters: a cost-benefit analysis. Am J Orthopsychiatry 1990; 60: 108-17.

7 Shanahan M, Donato R. Counting the cost: estimating the economic benefit of pedophile treatment programs. Child Abuse Negl 2001; 25: 541-55.
8 Palmer S, Davidson K, Tyrer P, Gumley A, Tata P, Norrie J, et al. The costeffectiveness of cognitive behavioural therapy for borderline personality disorder: results from the BOSCOT trial. J Pers Disord 2006; 20: 466-81.

9 Philips Z, Ginnelly L, Sculpher M, Claxton K, Golder S, Riemsma R, et al. Review of guidelines for good practice in decision-analytic modelling in health technology assessment. Health Technol Assess 2004; 8: 1-172.

10 Lipscomb J, Weinsten MC, Torrance GW. Time preference. In Costeffectiveness in Health and Medicine (eds MR Gold, JE Seigel, LB Russell, MC Weinsten): 214-46. Oxford University Press, 1996.

11 National Institute for Health and Clinical Excellence. Guide to the Methods of Technology Appraisal. NICE, 2004.

12 Appleton C, Roberts C. The Resettlement of Discretionary Life-Sentenced Offenders. Development and Practice Report 44. Home Office, 2005.

13 HM Prison Service. Prison Service Annual Report and Accounts. TSO (The Stationery Office), 2006.

14 Department of Health. Reference Costs 2006. Department of Health, 2007

15 Fortune Z, Barrett B, Armstrong D, Coid J, Crawford MJ, Mudd D, et al. Clinical and economic outcomes from the UK pilot psychiatric services for personality-disordered offenders. Int Rev Psychiatry 2011; 23: 61-9.

16 HM Treasury. The Green Book: Appraisal and Evaluation in Central Government. TSO (The Stationery Office), 2003.

17 Van Hout BA, Al MJ, Gordon GS, Rutten FH. Costs, effects and costeffectiveness ratios alongside a clinical trial. Health Econ 1994; 3: 309-19.

18 Dubourg R, Hamed J. The Economic and Social costs of Crime Against Individuals and Households 2003/4. Home Office Online Report 30/05. Home Office, 2005.

19 Brand S, Price R. The Economic and Social Costs of Crime. Home Office Research Study 217. Research, Development and Statistics Directorate, Home Office, 2000.

20 Dolan P, Loomes G, Peasgood T, Tsuchiya A. Estimating the intangible victim costs of violent crime. Br J Criminol 2005; 45: 958-76.

21 Drummond M, Sculpher M, Torrance GL, O'Brien BJ, Stoddart GL. Methods for the Economic Evaluation of Health Care Programmes (3rd edn). Oxford University Press, 2005.

22 Fenwick E, Byford S. A guide to cost-effectiveness acceptability curves. Br J Psychiatry 2005; 187: 106-8.

23 Bradley K. Lord Bradley's Review of People with Mental Health Problems or Learning Disabilities in the Criminal Justice System. Department of Health, 2009. 